\title{
Deteccção do DNA de Mycobacterium leprae em secreção nasal
}

\author{
Detection of Mycobacterium leprae DNA in nasal swab
}

Detección del ADN de Mycobacterium leprae en secreción nasal

\author{
Ana Rosa Botelho Pontes ${ }^{\prime}$, Maria das Graças Carvalho Almeida", \\ Marília Brasil Xavier"II, Juarez Antonio Simões Quaresma"I, Edna Aoba Yassuil"I \\ 'Universidade Federal do Pará. Curso de Enfermagem. Belém. PA \\ "Universidade do Estado do Pará. Curso de Enfermagem. Belém, PA \\ I'Universidade Federal do Pará. Programa de Pós-Graduação em Doenças Tropicais. Belém, PA
}

Submissão: 29/08/2008

Aprovação: 17/10/2008

\section{RESUMO}

Estudos têm demonstrado alta sensibilidade da técnica da reação em cadeia de polimerase (PCR) na identificação do DNA do Mycobacterium leprae. Este estudo objetivou avaliar a sensibilidade da PCR na detecção do DNA do M. leprae em "swab" nasal de pacientes hansenianos e comparar os resultados com a baciloscopia e formas multibacilares (MBs) e paucibacilares (PBs). Foram coletadas amostras de secreção nasal de 24 pacientes hansenianos, conservadas em solução de lise um e dois. Os resultados da PCR foram altamente significativos $(p<0.0000)$ e revelaram maior sensibilidade do Que a baciloscopia, nas diversas formas clínicas. Contudo, são necessários ainda outros estudos, testando novos marcadores e conservantes, com o intuito de elevar a sensibilidade dessa técnica, em amostras de secreção nasal. Descritores: Hanseníase; Mycobacterium leprae; PCR; Pesquisa em enfermagem.

\begin{abstract}
Studies have demonstrated high sensibility of the polimerase chain reaction (PCR) technique in the identification of the Mycobacterium leprae DNA. This study aimed to evalue the PCR sensibility at the detection of the M. leprae DNA in nasal swab of leprosy patients and to compare the results with the bacilloscopy and multibacillary (MBs) and paucibacilares (PBs) forms. Nasal secretion samples of 24 leprosy patients were collected, and were preserved in one and two lise's solution. The PCR results were highly significant $(p<0.0000)$ and they revealed grater sensibility than bacilloscopy, in several clinical forms. Nevertheless, still different studies are necessary, testing new markers and preservatives, with the purpose of lifting up the sensibility of this technieue, in nasal secretion samples.

Descriptors: Leprosy; Mycobacterium leprae; Polymerase Chain Reaction; Nursing research.
\end{abstract}

\section{RESUMEN}

Los estudios han demostrado una alta sensibilidad de la técnica de Reacción en Cadena de la Polimerasa (PCR) para identificar el ADN de Mycobacterium leprae. El objetivo del estudio fue evaluar la sensibilidad de la PCR en la detección de ADN de $M$. leprae en hisopo nasal de los pacientes hansenianos y comparar los resultados con la baciloscopía y las formas multibacilares (MBs) y paucibacilares (PBS). Se obtuvieron muestras de secreción nasal de 24 pacientes hansenianos, conservados en solución de lisis uno y dos. Los resultados de la PCR fueron muy significativas ( $p$ < 0000) y mostró una mayor sensibilidad que la baciloscopía, en diferentes formas clínicas. Sin embargo, otros estudios son aún necesarios, el ensayo de nuevos marcadores y conservantes con el fin de aumentar la sensibilidad de esta técnica, en muestras de secreción nasal.

Descriptores: Lepra; Mycobacterium leprae; Reacción en cadena de la polimerase; PInvestigación en enfermería. 


\section{INTRODUÇÃO}

A hanseníase é uma doença infecciosa crônica, causada pelo Mycobacterium leprae, Que afeta predominantemente a pele, nervos periféricos e membranas mucosas, com alta prevalência no mundo, constituindo uma das endemias de prioridade pela Organização Mundial da Saúde (OMS) pelo seu poder incapacitante, Que marginaliza e interrompe a capacidade produtiva de milhares de pacientes $^{(1)}$.

O homem é considerado como a única fonte de infecção. E o principal meio de transmissão da doença é provavelmente pela propagação de aerossol de secreções nasais e gotículas do trato respiratório de pacientes não tratados, embora possa ocorrer pelo contato com a pele não íntegra. Vários estudos indicam que a transmissão ocorre principalmente pela inalação e a cavidade nasal seria a porta de entrada e saída do bacilo ${ }^{(2-4)}$.

O aparecimento da doença e suas diferentes manifestações clínicas dependem, dentre outros fatores, da relação bacilo/hospedeiro e pode ocorrer após um longo período de incubação, de 2 a 7 anos. Dentre as pessoas que adoecem, algumas apresentam resistência ao bacilo, constituindo os casos paucibacilares (PB) com baixa carga bacilar, insuficiente para infectar outras pessoas, portanto, não sendo consideradas fontes importantes de transmissão. Um número menor de pessoas não apresenta resistência ao bacilo, Que se multiplica no organismo passando a ser eliminado para o exterior, podendo infectar outras pessoas, constituindo casos multibacilares (MB), considerados fonte de infecção e manutenção da cadeia epidemiológica da doença( ${ }^{(5)}$.

Tendo em vista que a hanseníase não é estável em sua forma clínica, Ridley e Jopling propuseram uma classificação com um sistema de cinco grupos Que expressavam a imunidade dos pacientes, em: lepromatoso (LL), borderline lepromatoso (BL) e boderline (BB) considerados multibacilares; borderline tuberculóide (BT) e tuberculóide (TT) como paucibacilares; além de uma forma clínica inicial, indeterminada (HI), Que pode evoluir para Quaisquer das formas anteriores $^{(6,7)}$.

O Brasil registrou um aumento de novos casos detectados de 34.235, em 1993, para 38.410 em 2006. Desses, 19.515 são multibacilar (MB). Embora tenha apresentado redução significativa de sua prevalência de 16,4/10.000 habitantes em 1985, para I,5/ 10.000 habitantes no início de 2006, aproximando-se da meta de eliminação proposta pela Organização Mundial de Saúde (OMS), de I caso/ I0.000 habitantes, continua ocupando o segundo lugar em números de casos e considerado pela OMS como área de alta endemicidade $^{(8)}$.

Apesar da importante redução do coeficiente de prevalência da hanseníase no Brasil, em 2006, somente as regiões Sul e Sudeste alcançaram a meta de eliminação, algumas regiões demandam intensificações das ações para eliminação, entre estas a região Norte ${ }^{(9)}$.

A hanseníase manifesta-se, inicialmente, através de lesões de pele: manchas esbranquiçadas ou avermelhadas com perda de sensibilidade, sem evidência de lesão nervosa troncular, Que ocorrem em QualQuer região do corpo, mas, com maior freqüência, na face, orelhas, nádegas, braços, pernas e costas, podendo acometer também a mucosa nasal. Com a evolução da doença, manifestam-se as lesões nervosas, principalmente nos troncos periféricos. Podem aparecer nervos enfartados e doloridos, diminuição de sensibilidade nas áreas por eles inervadas, como olhos, mãos e pés, assim como redução da força muscular pelos nervos comprometidos. Essas lesões são responsáveis pelas incapacidades e deformidades características da hanseníase $e^{(5)}$.

A identificação do $M$. leprae é difícil devido à inabilidade do bacilo para crescimento in vitro. O diagnóstico da hanseníase é baseado na detecção microscópica do bacilo álcool ácido resistente (BAAR) em esfregaço de tecido em combinação com a avaliação clínica e histopatológica. Entretanto, a baciloscopia, apresenta baixa sensibilidade por requerer, no mínimo, para sua detecção, de $10^{4}$ microorganismos por grama de tecido ${ }^{(10)}$.

A PCR apresenta posição de destaque dentre os exames de alta sensibilidade pela possibilidade de amplificar fragmentos de DNA de células, inserindo as bacterianas, permitindo, desta forma, sua fácil detecção( ${ }^{(1)}$. A introdução recente dessa técnica forneceu oportunidade sem precedentes para detecção específica, sensível e rápida do DNA do $M$. leprae em espécimes clínicas. Estudos utilizando biópsias de pele de pacientes com hanseníase têm demonstrado Que a técnica da PCR apresenta maior sensibilidade da detecção do bacilo, sugerindo vantagem Quando comparada ao exame histopatológico e baciloscópico convencionais ${ }^{(12)}$.

Inúmeras amostras clínicas podem ser usadas para a detecção do bacilo $M$. leprae, através da PCR, entre elas, raspado celular, sangue, biópsia de pele e nervo e secreção nasal ${ }^{(13)}$. Neste estudo, procuramos avaliar a sensibilidade da PCR na detecção de $M$. leprae em secreção nasal de pacientes hansenianos, conservando as amostras em diferentes soluções e condição de armazenamento, comparando os resultados com a baciloscopia e formas clínicas.

\section{MÉTODO}

População de Estudo - Foram incluídos 24 pacientes, atendidos no ambulatório do Núcleo de Medicina Tropical (NMT) da Universidade Federal do Pará (UFPA), em Belém e no Hospital Municipal de Itaituba, portadores das diversas formas clínicas da hanseníase, diagnosticados e classificados segundo os critérios clínicos e laboratoriais do Ministério da Saúde - Brasil, no período de maio de 2006 a agosto de 2007.

Este trabalho foi aprovado pelo Comitê de Ética do NMT da UFPA, sob o no 10/2006-CEP/NMT, e todos os indivíduos Que participaram do estudo foram informados sobre a pesquisa, de maneira acessível, sendo solicitado assinatura de um Termo de Consentimento Livre e Esclarecido, conforme rege a Resolução 196/96, do Conselho Nacional de Saúde.

\section{Coleta e Processamento de Amostras}

Inicialmente os pacientes passaram por uma avaliação clínica, realizada por médicos do Ambulatório no NMT da UFPA, com vistas à análise da real necessidade de exames laboratoriais e moleculares para o tratamento da doença. Após a obtenção do consentimento de todos os pacientes, foram coletadas, de cada um, duas amostras de secreção nasal com o auxílio de "swabs" estéreis (CB Products Indústria Brasileira) esfregando suavemente várias vezes contra o segmento anterior da cavidade nasal. Após a colheita da secreção nasal, o final do "swab" foi cortado, sendo um "swab" imerso em $400 \mathrm{ml}$ de solução de LISE UM $(\mathrm{lmg} / \mathrm{ml}$ de proteinase $\mathrm{K}$ em 100 
$\mathrm{mM}$ de Tris- $\mathrm{HCl}, \mathrm{pH} 8,5,0,05 \%$ Tween 20) e refrigerado imediatamente. E o outro "swab" imerso em $400 \mathrm{ml}$ de solução de LISE DOIS ( $10 \mathrm{mM} \mathrm{NaCl}, 10$ mM EDTA, I mM Tris, 1\% SDS) e mantido em temperatura ambiente. Em seguida, as amostras foram transportadas ao laboratório de Biologia Molecular do NMT da UFPA, para análise. O processamento das amostras foi conforme descrito na literatura por Jadhav et $\mathrm{al}^{(14)}$ e Sambrook et $\mathrm{al}^{\mathrm{I}^{(15)}}$. Dois microlitos (2ml) da amostra foram usados em cada reação de PCR.

\section{Baciloscopia}

Foram coletadas, ainda, de cada paciente duas amostras de linfa do lóbulo da orelha direita e esQuerda, cotovelo direito ou esQuerdo e da lesão, após excisão local com bisturi para preparação de lâminas de rotina, com vistas à pesQuisa de bacilos álcool-ácido resistentes. Esse procedimento foi realizado no Laboratório de análises clínicas do NMT da UFPA.

\section{Análise dos dados}

A análise estatística foi realizada utilizando o aplicativo BIOESTAT 3.0 ${ }^{(16)}$. Os resultados foram comprovados pelo Teste $\mathrm{Q}$ de Cochran e Teste de Correlação Linear de Pearson. A significância estatística adotada foi menor ou igual a 0,05 em todos os testes.

\section{RESULTADOS}

\section{Baciloscopia}

Dos vinte e Quatro pacientes estudados, dezesseis foram classificados como multibacilares (MB) e oito como paucibacilares (PB). Comparando a classificação com os resultados da baciloscopia, seis dos pacientes MB apresentaram resultado positivo (25\%) e dez resultado negativo $(41,67)$ e todos os oito paucibacilares tiveram resultado negativo $(33,33 \%)$.

\section{Reação em cadeia de polimerase}

Com relação aos conservantes de solução de lise um e lise dois, os estudos demonstraram Que os resultados da PCR foram altamente significantes nas amostras de secreção nasal $(p<0.0000)$ Quando conservadas em lise um. Com relação à solução de lise dois, os resultados apontaram uma funcionalidade não significativa $(p=1.0000)$. Diante do exposto, os resultados confirmaram Que a solução de lise um apresentou maior positividade nos resultados da PCR, Quando comparada com a solução de lise dois, independente da classificação operacional da doença. $\mathrm{a}=0,05$ - Teste $\mathrm{Q}$ de Cochran.

Comparando os resultados da PCR com a baciloscopia, os estudos apontaram Que a PCR obteve maior sensibilidade para as formas multibacilares $(41,67 \%)$, seguida da baciloscopia (25\%). Nas formas paucibacilares, a baciloscopia não apresentou sensibilidade (0\%).

Para medir o grau de dependência entre os resultados da PCR, nas amostras clínicas de secreção nasal, conservadas em solução de lise um e a baciloscopia, foi aplicado o Teste de Correlação Linear de Pearson Que considerou não significativa a correlação entre os resultados da PCR e a baciloscopia $(r=0,3849$ e $p=0,0632)$.

\section{DISCUSSÃO}

A baciloscopia apresenta uma baixa sensibilidade, devido requerer no mínimo $10^{4}$ organismos por grama de tecido, especialmente, em pacientes paucibacilares ${ }^{(10)}$. O estudo em Questão apontou Que a baciloscopia apresentou maior sensibilidade nas formas multibacilares, do que nas paucibacilares, independente dos tipos de conservantes e temperatura, conforme mencionadas na metodologia.

As lesões de pele são consideradas um dos sinais cardinais da hanseníase e, em associação com o exame clínico, seria o diagnóstico "padrão ouro" para a hanseníase. Entretanto, a sensibilidade das lesões isoladas é baixa. Assim, o método da PCR para identificação do DNA foi introduzido como um método de diagnóstico Que apresenta maior sensibilidade e especificidade do que a baciloscopia $^{(10)}$.

Os resultados evidenciaram Que as amostras de secreção nasal, conservadas em solução de lise um, mantidas sob refrigeração, apresentaram maior positividade $(\mathrm{P}<0.0000)$, independente da classificação das categorias paucibacilares e multibacilares. Conforme a literatura, a rota da infecção da hanseníase permanece ainda desconhecida, embora diversos estudos apontem a via nasal como a porta de entrada e saída da bactéria ${ }^{(17)}$.

Estudos revelaram um valor potencial dos testes de diagnóstico da PCR em biópsias de mucosa nasal de pacientes e seus contatos. A identificação do ponto inicial da infecção seria o mais difícil e importante no estudo da transmissão do $M$. leprae. O PCR demonstra ser um método de diagnóstico promissor na mensuração da infecção subclínica. Provavelmente, um número de indivíduos infectados definidos como assintomáticos existe e devem ter função ativa na transmissão da doença ${ }^{(18)}$. Essa proposição foi visualizada nos resultados obtidos neste estudo, no momento em Que foi revelada alta positividade nas amostras de secreção nasal $(\mathrm{P}<0.0000)$.

Vários estudos são unânimes em confirmar a presença de bacilos no muco nasal, considerando de valor diagnóstico o exame deste, bem como profilático associado com o exame clínico e a pesquisa de bacilos nas lesões cutâneas.

Nestes estudos, os resultados da PCR revelaram Que o número de casos positivos é maior nas formas multibacilares do Que nas formas paucibacilares, expressando maior carga bacilar nas formas MB do Que nas PB. Entretanto, considerando Que os tipos PB carregam poucos organismos Que nenhum desses casos seria detectado por análise microscópica, os $36.4 \%$ de positividade da PCR se tornou mais significativo, mostrando claramente uma vantagem em torno da microscopia ${ }^{(19)}$. Nesta pesquisa, os resultados foram concordantes com o autor referido, confirmando Que as formas multibacilares apresentam maior positividade para a PCR (20,83\%) do Que as formas paucibacilares $(4,16 \%)$, contudo, a PCR identificou o DNA do $M$. leprae em dois dos oito pacientes paucibacilares.

Vários estudos, na literatura, têm usado o tampão de lise um, descrito por De Wit et al ${ }^{(20)}$ para a conservação de diversas amostras biológicas, na detecção de $M$. leprae, pela PCR, demonstrando sensibilidade significativa nos resultados. Assim, neste trabalho, os resultados revelaram Que a solução de Lise um, conservada sob refrigeração, evidenciou maior positividade nos resultados da PCR, em Quanto Que a solução de lise dois, mantida em temperatura ambiente, não demonstrou funcionalidade, provavelmente pela interferência de fatores, como, tempo de espera para análise e a conservação em temperatura ambiente; não alcançando, dessa forma, o objetivo almejado de sua aplicação em pesQuisas de campo.

A correlação entre os resultados da PCR, em amostras de secreção nasal, conservadas em solução de lise um e a baciloscopia foi 
considerada não significativa, pelo Teste de Correlação Linear de Pearson, ou seja, os resultados da PCR não apresentaram grau de dependência com a baciloscopia $(r=0.3849$ e $p=0.0632)$. Se a baciloscopia fosse o único critério para a classificação dos pacientes, $20 \%$ dos casos MBs seriam considerados como PBs, segundo os autores Andrade e et $\mathrm{a}^{(21)}$. A baciloscopia mostra-se negativa $(\mathrm{IB}=0)$ nas formas tuberculóide e indeterminada, fortemente positiva na forma virchowiana e revela resultado variável na forma dimorfa ${ }^{(22)}$.

Estudos confirmam Que dos 10,4\% dos pacientes multibacilares são classificados pela baciloscopia como paucibacilares. Esse erro na classificação dos pacientes conduziria a um tratamento inadeQuado, aumentando o risco de recidivas e o período em que o paciente se mantém como fonte de infecção. Por outro lado, dos pacientes definidos como paucibacilares pela baciloscopia, 16,2\% eram multibacilares, sendo submetidos desnecessariamente a tratamentos Que provavelmente poderiam levar efeitos adversos graves e a elevação dos gastos nos serviços de saúde, bem como, sobrecarga para a equipe de monitoramento desses pacientes ${ }^{(23)}$.

\section{CONSIDERAÇÕES FINAIS}

Neste estudo a PCR, usando amostras de secreção nasal, não demonstrou ser o método mais eficaz para identificação do $M$. leprae. Como perspectivas, outras pesquisas, incluindo novos marcadores e conservantes, seriam necessárias para elevar a sensibilidade desse método, com o intuito de monitorar o tratamento e à cura dos pacientes hansenianos, evitando, assim, a utilização de outros métodos de diagnósticos invasivos para o controle dessa doença.

\section{REFERÊNCIAS}

I. Hastings RC, GillsTP, Krahenbuhl JL, Franzblau SG. Leprosy. Clinical Microbiol Rev 1988; 330-48.

2. Job CK. Nasal mucosa and abraded skin are the two routes of entry of M. leprae. Star 1990; 49 (3): 1.

3. Job CK, Drain V, Williams DL, Gillis T P. Comparison of polymerase chain detection technique with other methods for detection of M. leprare in tissues of wild ninebanded armadilhos. Lepr Rev 1991; 62: 362-73.

4. Mcdermott-Lancaster RD, Mc-Dougall AC. Mode of transmission and histology of $\mathrm{M}$. leprae infection in nude mice. Int I Exp Pathol 1990; 71: 689-700.

5. Wordl Health Organization. Leprosy for medical practitioners and paramedical workers. Geneva: Novartis Foundation for Sustainable Development; 2002.

6. Matos HJ, Duppre N, Alvim MFS, Vieira LMM, Sarno EN. Leprosy epidemiology in a cohort of household contacts in Rio de laneiro (1987-1991). Cad Saúde Pública 200 I 1 15:533-42.

7. Santos AR, Balassiano V, Oliveira MLW, Pereira MAS, Santos PB et al. Detection of Mycobacterium leprae DNA by polymerase chain reaction in the blood of individuals, eight years after completion of anti-leprosy therapy. Mem Inst Oswaldo Cruz 2001; 96(8): 1129-33.

8. World Health Organization. Global leprosy situation, 2006. Weekly Epidemiol Record 2006; 32: 309-16.

9. World Health Organization. Global leprosy situation, 2005. Weekly Epidemiol 2005.

10. Almeida EC, Martinez AN, Maniero VC, Sales AM, Duppre NC et al. Detection of Mycobacterium leprae DNA by polymerase chain reaction in the blood and nasal Mycobacterium leprae secretion of Brazilian household contacts. Mem Inst Oswaldo Cruz 2004; 99(5): 509-12.

11. Santos GG, Marcucci G, Júnior JG, Margarido LC, Lopes LHC. Pesquisa de Mycobacterium leprae em biópsias de mucosa oral por meio da reação em cadeia de polimerase. Anais Bras Dermatol 2007; 82: 245-9.

12. Martelli CMT, Stefani MM, Penna GO, Andrade ALSS. Endemias

e epidemias brasileiras, desafios e perspectivas de investigação científica: hanseníase. Rev Bras Epidem 2002; 5.

13. Santos AR, Degrave WM, Suffys PN. Use of polymerase chain reaction in Leprosy research. Indian I Lepr 1999; 71:101-10.

14. Jadhav RS, Macdonald M, Brune G, Oskaml. MILEP2 Study Group. Simplified PCR detection method for nasal Mycobacterium leprae. Int I Lepr Other Mycobact Dis 200I; 69: 299-307.

15. Sambrook J, Frisch EF, Maniatis T. Molecular clonig: a laboratory manual. New York: Cold Spring Harbor Laboratory; 1989.

16. Ayres M, Ayres MJ, Ayres DL, Santos AS. Bio Estat 3.0 Aplicações estatísticas nas áreas das ciências biológicas e médicas. Sociedade Civil Mamirauá. MCT - CNPQ; 2004.

17. Groathouse NA, Rivoire B, Kim K, Lee H, CHO, et al. Multiple polymorphic loci for molecular typing of strains of Mycobacterium leprae. I Clinical Microbiol 2004; 1666-72.

18. Patrocinio LG, Goulart IMB, Goulart LR, Patrocínio IA, Ferreira FR. Detection of M. Leprae in nasal mucosa biopsies by the polymerase chain reaction. Immunol Med Microbiol 2005; 44(3): 311-6.

19. Wichttwechkarn J, Karnjan S, Shuntawuttisettee S, Sornprastt C, Kampirapap K, et al. Detection of Mycobacterium leprae Infection by PCR. I Clinical Microbiol 1 995; 33(I): 45-9.

20. Wit MYL, Douglas IT, Mcfadden I, Klastser PR. Polymerase chain reaction for the detection of Mycobacterium leprae in nasal swab specimes. I Clinical Microbiol 1993.

21. Andrade VLG, Moreira TA, Avelleira ICR, Marques AB, Bayona M. Paucibacilar ou Multibacilar? Uma contribuição para os serviços de saúde. Hansen Int 1996; 2 I (2): 6-13.

22. Araujo MG. Hanseníase no Brasil. Rev Soc Bras Med Trop 2003; 36(3).

23. Gallo MEN, Júnior LANR, Albuquerque ECA, Nery JAC, Sales AM. Alocação do paciente hanseniano na polieuimioterapia: correlação da classificação baseada no número de lesões cutâneas com os exames baciloscópicos. Rev Bras Dermatol 2003; 78(4): 415-24.

Agradecimentos: Ao CNPQ pelo suporte financeiro e ao Núcleo de Medicina Tropical da Universidade Federal do Pará pela viabilização deste estudo. 